\title{
Dietary Phytochemical Index and Psychological Disorders in a large sample of Iranian adults: a population-based study
}

zahra darabi

Shahid Sadoughi University of Medical Sciences and Health Services

azam Ahmadi Vasmehjani

Shahid Sadoughi University of Medical Sciences and Health Services

amin Salehi-Abargouei

Shahid sadoghi medical university

masoud mirzaei

Shahid Sadoughi University of Medical Sciences and Health Services

Mahdieh Hosseinzadeh ( $\sim$ hoseinzade.mahdie@gmail.com )

Shahid Sadoughi University of Medical Sciences https://orcid.org/0000-0001-7482-2494

Research article

Keywords: Psychological, diet, nutrition, food

Posted Date: November 11th, 2020

DOI: https://doi.org/10.21203/rs.3.rs-102000/v1

License: (c) (1) This work is licensed under a Creative Commons Attribution 4.0 International License. Read Full License 


\section{Abstract}

Background: Intake of plant foods including of Phytochemicals may be decrease risk of mental health.

Aim: This study aim to investigate association of Dietary Phytochemical Index)DPI( with symptoms of depression, anxiety and stress in a large sample of Iranian adults.

Methods: In this cross-sectional study, a total of 7385 adult aged

20-50 years old were provided from the recruitment phase of Yazd Health Study, a population-based cohort research on Iranian adults. Food intakes were assessed via

validated and reliable food frequency questionnaire. Symptoms of depression, anxiety and stress were assessed using a validated Depression, Anxiety and Stress Scales questionnaires with 21-items. DPI was calculated by percent of daily energy intake taken from phytochemical-rich foods.

Results: After adjusting for potential confounders, normal weight subjects in the highest tertile of DPI had a lower risk of depression (OR: $0.65 ; 95 \% \mathrm{Cl}: 0.44-0.97)$ and anxiety symptoms (OR: 0.65; 95\% Cl: 0.45-0.93) compared with those in the lowest tertile. However, no apparent association was found between depression, anxiety and stress in overweight and obese subjects.

Conclusion: We found significant association between DPI and mental health in normal weight adults. Prospective studies are required to approve these conclusions.

\section{Background}

The most common psychiatric disorders, depression and anxiety, are among the important comprehensive health problems (1). Results of previous studies reported the prevalence of major depressive disorder and anxiety was $4.7 \%$ and $7.3 \%$ in the worldwide respectively $(1,2)$. The prevalence of psychiatric disorders was $10.81 \%$ in IRAN. It is reported that at least around 7 millions of Iranian population endure from one or more of the psychiatric disorders (3). Since psychiatric disorders force a powerful economic burden and help to impairment quality of life, it is critical to find suitable approach to prevent and treatment of this disorders (4).

Previous researches shown that diet significantly associated with psychiatric disorders $(5,6)$. Results of cross sectional study shown that high intake of healthy foods such as vegetables and fruits and low intake of unhealthy foods such as soda, french fries, fast food, sweetened fruit drinks, cake, cookies, pie, ice cream and frozen desserts inversely associated with risk psychological distress (5). Another study showed intake of fruit and vegetable reduced risk of depression and also intake of added sugars increased risk of anxiety in males (6).

Food groups such as fruits, vegetables, whole grains, nuts, legumes and essential oils are rich of phytochemicals that have antioxidant and anti-inflammatory properties $(7,8)$. Phytochemicals are natural, non-nutritive bioactive compounds and include of other plant foods such as phenolic compounds, isoperenoids, and organosulfor compounds (4). Main potential effects of phytochemicals are anti-estrogenic, immunomodulatory, cardioprotective, anti-carcinogeni, anti-inflammatory and anti-oxidant activities (9-11). Based on health booster effect of phytochemicals, McCarty proposed a dietary phytochemical index (DPI), which was characterize according to the percent of daily energy intake taken from phytochemical-rich foods. DPI could be a good indicator of diet quality and may be useful in clinical purposes (12).

Several studies have been evaluated the association between DPI and health status for instances, one study showed that higher score of DPI associated with a lower risk of abdominal obesity and hypertriglyceridemia (13). Another study reported the risk of hyperinsulinemia significantly decreased in the higher quartiles of DPI after 3-years of follow-up (14). Results of pervious study shown that inflammation and oxidative stress role play in the

Page $2 / 15$ 
pathophysiology of psychiatric disorders $(15,16)$. Due to the anti-inflammatory and antioxidant effects $(8)$, it has been suggested this index as mental-protective. Few studies investigated relationship between dietary phytochemical index and psychological disorders, the aim of study investigated the association between DPI and symptom of depression, anxiety, and stress among a large sample of Iranian adults.

\section{Methods}

\section{Study design and participants}

This cross-sectional study was performed on within the framework of Yazd Health Study (YaHS) and Taghzieh Mardom-eYaZd (TAMYZ). Detailed information about the study design, sampling procedures, participants' characteristics and data collection process has been previously published (17). Briefly, YaHS was a prospective cohort which carry out 10000 participants of the adult population aged 20-70 years old inhabit in Yazd city during 2014-2016. The participants were from 200 clusters involve 50 people ( 5 males and 5 females from each age10 years groups) that were randomly chosen from Yazd community based on residential postal codes. TAMEZ is an ongoing population based cross-sectional study that it assessed the dietary food and supplement intake of people living in Yazd city. All 10,000 participants of YaHS are included in TAMEZ. In this study, we used data from 7385 adults (49.7\% male \& $50.3 \%$ female) whose both psychological profile and dietary intake information had been completed at the time of analysis.

\section{Dietary assessment}

Dietary assessment in TAMYZ study done via validated 178 item food frequency questionnaire (FFQ) which modified version of a previously validated 168-item that 10 questions particularize consumption of Yazd-specific food items were added to the original 168-

item FFQ, due to a178-item FFQ (17). Participants were asked that reported the frequency and usual amount intake of item food then converted to grams using guidelines of household scales (18).

\section{Phytochemical index calculation}

The DPI was compute based on the method developed by McCarty in 2004; [[DPI = (daily energy derived from phytochemicalrich foods $(\mathrm{kcal}) /$ total daily energy intake $(\mathrm{kcal})) \times 100](12)$. Fruits, vegetables, legumes, whole grains, nuts, soy products, seeds and olive oil were considered as phytochemical-rich foods. Potatoes were not included as vegetables because their low phytochemicals content. Natural fruit and vegetable juices as well as tomato sauces were included in the fruit and vegetable groups because these are also considered as their high phytochemical content (19).

\section{Assessment of psychological profile}

The psychological condition of the participants was assessed via the validated Depression, Anxiety and Stress Scales (DASS21) questionnaire(20). Each part of DASS-21 (depression, anxiety, psychological distress) consist of 7 questions. The response were divided into: zero,

low, medium, and high with a score between 0 and 3, respectively. DASS-21 is the shorten DASS-42. So, the total points for each item should be duplicated by 2 . Therefore, depression, anxiety, and stress are characterized by the following scores: $\geq 10, \geq 8$ and $\geq 15$, respectively.

\section{Anthropometric assessments}

Body weight was measured with the minimum possible cloths and barefoot standing in the middle of Omron BF511 (Japan) portable digital. Height was determined to the nearest $0.1 \mathrm{~cm}$ in a standing position using a stadiometer with shoulders in a relaxed position and arms hanging freely and without shoes. Body Mass Index (BMI) $(\mathrm{kg} / \mathrm{m} 2)$ was calculated through the following formula: weight $(\mathrm{kg})$ divided by height squared $(\mathrm{m} 2)$. 


\section{Physical activity assessment}

Physical activity was determined International Physical Activity Questionnaire (IPAQ). This Questionnaire classifies the population into three groups of low, medium, high activity based on MET (Metabolic Equivalent) (21).

\section{Assessment of other variables}

Data about age, gender, marital status, education level, job and history of chronic disease was collected via self-administered questionnaire.

\section{Statistical analysis}

General characteristics across tertile of DPI were expressed as means \pm SDs and numbers and percentages for continuous and categorical variable respectively. Also for examine the differences across tertiles ANOVA and Chi square test were used for continuous and categorical variable respectively. Binary logistic regression has been used in crude and multivariableadjusted models to determined ORs and $95 \%$ Cls for psychological profile across tertiles of DPI. First, we controlled for age (continuous), sex (categorical) and energy intake $(\mathrm{kcal} / \mathrm{d})$ then for marital status (married, single and widowed or divorced), physical activity (sedentary/moderate/active), intake of supplement (never, 1-3 in mount, 2-4 in week, 5-6 in week, one a day, two a day and more than two a day), employment status (unemployed, government employee, manual worker and freelance job) and education statues (illiterate, middle school, associate囚 degree, bachelor's degree, master》 degree and doctor), history of chronic disease (yes/no, including: hypertension, diabetes, cardiovascular disease, cancer and dyslipidemia) and special diet (yes, no). Stratified analyses by BMI status (over weight and obese $>24.9$ and normal weight $\leq$ $24.9 \mathrm{~kg} / \mathrm{m}^{2}$ ) were also done in crude and adjusted models. $P$ trend was determined by considering tertiles of DPI as ordinal variables in the logistic regression analysis. All statistical analyses were performance using SPSS version 23 . P $<0.05$ was designed to be statistically significant.

\section{Results}

\section{Characteristics of participants}

Psychological status of the participants reported in Table 1. The prevalence of depression, anxiety and stress $8.1 \%, 10.5 \%$ and $3.3 \%$ was respectively in the study population. The general, demographic and anthropometric characteristics of the study population across tertiles of DPI

are presented in Table 2. No significant difference was seen in marital status, physical activity, intake of supplement, employment status, education across tertiles of DPI but age of participants, history of chronic disease and special diet was significant between tertiles. Weight and BMI significantly greater in highest tertile of DPI compare to lowest tertile. Food groups and nutrients intake of study population across tertile categories of DPI are reported in Table 2. Subjects in the highest tertile of DPI compared to those in the lowest tertile had lower intakes of vitamin E, vitamin B2, vitamin B12, vitamin D, total fat, monounsaturated fatty acids (MUFA), saturated fatty acids (SFA), and higher intake of Fe, Mg, vitamin A, vitamin B1, folic acid, biotin, pantothenic acid and vitamin C. Also, subjects in higher tertile had significantly lesser energy intake compare to subjects in lowest tertile (data not shown).

\section{Psychological status and DPI}

Mental health across tertiles of DPI for the participant in crude and adjusted OR ( $95 \% \mathrm{Cls}$ ) stratified by BMI are shown in Table 4. In subjects with normal weight (BMI $\leq 24.9)$, a significant protective association was found between DPI and odds of depression (OR: 0.82; 95\% Cl: 0.68-0.99; $\mathrm{p}=0.04$ ) and anxiety (OR: 0.83; 95\% Cl: 0.71-0.98; $\mathrm{p}=0.03$ ) in crude model. Also, there was a significant decreasing trend in the odds of anxiety and depression across increasing tertiles of the DPI (P-trend: 0.03 ) and (P-trend: 0.04) respectively. This association remained significant after adjusting for potential confounders including weight, BMI, marital status, physical activity, intake of supplement, employment status, education, history of chronic 
disease and special diet for depression (OR: 0.79; 95\% Cl: 0.64-0.97; $p=0.02)$ and anxiety (OR: $0.79 ; 95 \%$ Cl: $0.66-0.95 ; p=$ 0.01). Also, there was a significant decreasing trend in the odds of anxiety and depression across increasing tertiles of the DPI (P-trend $=0.02$ and 0.01 respectively). There was no significant association between stress and tertiles of DPI in crude and adjusted model.

However, in overweight and obese subjects, no significant association between tertiles of DPI and psychologic disorders were observed both in crude and adjusted model .

\section{Discussion}

In the current study evaluating the relation between DPI and psychologic disorders, we observed that higher intake of phytochemical-rich foods was inversely associated with risk of depression and anxiety symptoms in participant with normal BMI. These protective relations remained significant after adjusting for a wide range of possible confounding variables. To the best of our knowledge, this study is among the first study exploring the DPI-psychological disorders relationship in a large population from a Middle-Eastern country where the prevalence of psychological disorders is higher than other part of the world (22).

A long-standing studies have been showed that food or dietary pattern with fluent phytochemical are protective for mental health, for instances, results of cohort study shown that high intake of flavonols, flavones and flavanones were inversely associated with risk of depression (23). Another study reported that high intake of phenolic acid, flavanones and anthocyanins significantly decrease risk of depressive (24). Some studies reported that "prudent", "lacto-vegetarian" and " healthy " dietary pattern characterized by high intakes of phytochemical rich foods including fruits, vegetables, medium fat dairy, nuts, legumes and fish was protectively associated with depression and anxiety $(22,25)$. In addition, some other studies confirmed the health benefit effects of DPI on abdominal obesity, lipid profile and insulin resistant $(13,14)$. In contrast with our results, a cohort study reported high intakes of flavan-3-ols and anthocyanins were not significantly associated with depression risk in women (23). Other study explained that higher consumption of high phytochemical foods such as fruits and vegetables was not associated with levels of depressive symptoms among males (26) Also, there was not any significant association between DPI and inflammatory markers as a mediator of psychological disorders in another research (27).

Inflammatory markers such as serum levels of C-reactive protein, tumor necrosis factor alpha and Interleukin 6 were related with mental health in previous studies $(28,29)$. So, the pro-inflammatory cytokines create numerous clinical distinct of depression such as disrupted serotonin metabolism, overactivity of the hypothalamus-pituitary-adrenal axis and

neurovegetative symptoms (30). Phytochemical disrupt production of pro-inflammatory mediators such as these derived from the arachidonic acid cascade. This derived components can be inflammatory effect via modulating neuro-inflammation by cooperation with p38 signaling cascades and STAT-1 (31). Fruits and vegetable are main sources of folate. Results of some studies shown that there are association between serum folate and dietary intake of this vitamin and depression (25, $32,33)$. It can be effect on mental health via methylation in the nervous system (32). Numerous psychiatric disorders were associated to oxidative stress. Brain is attainted especially susceptible to oxidative damage. Brain relatively consumes high oxygen and consequently higher production of free radical also brain has lipid-rich structure that vulnerable for oxidation (34, 35). Phytochemical are powerful antioxidants. It by donating an electron or hydrogen atom can able to neutralize free radicals (8).

Our results showed no significant association between stress and DPI. Few studies investigated association between food group and symptom stress. Results of cohort study shown that Mediterranean Diet Score was inverse association with psychological distress. This score was computed on the basis frequencies of intake vegetables, fruit, cereals, legumes and fish (36). The results of our studies were inconsistent with previous studies. The reason for inconsistency probably was using different questionnaires to diagnose psychological distress. Also one study conducted only on 488 women while sample sizes of our study are higher and conducted both men and women. 
There was no any significant association between DPI and psychological disorders in overweight and obese subjects. Few studies investigated association between food groups and psychological disorders in overweight and obese subjects. In consistent with our, other study reported that there was no association between traditional and lactovegetarian dietary pattern with high DPI-food such as vegetables, fruit and wholegrain

and psychological disorders in obese participant (22). Probably obesity can cause mental disorders in other ways, which has mitigated the phytochemical effects on mental disorders. Obese and overweight usually have negative body image. There is evidence that shown relationship between depressive symptoms and anxiety with body image dissatisfaction (37). Some studies revealed that obesity acts a role in development of psychopathological disorders such as anxiety and psychosis via begin low self-esteem $(38,39)$.

This study has several strengths. We adjusted for a wide range of potential confounders that might affect psychological conditions, also the large represented sample size of the study including both sexes. Stratified results base on BMI as an important dietary variable related with psychological disorders was presented. This study has some limitations. First the cross-sectional study was not show causal relationship between mental health and DPI. Second we undertake to control for manifest confounding factors however may has been some residual confounding. Third DPI does not include non-caloric phytochemical-rich food such as green and black tea that are sources of phytochemicals. finally, DASS questionnaire do not provide diagnostic of disorders and only estimate symptoms of depression and anxiety.

\section{Conclusion}

We understand that higher score of DPI including fruits, vegetable, nuts, olive and olive oil, legumes and whole grains was correlate with a lower risk of depressive symptoms and anxiety in subjects with normal BMI, but not in over weight subjects. These findings need to be examined with prospective studies so verify the causality between DPI and mental health.

\section{Abbreviations}

DPI: Dietary Phytochemical Index, DASS:Depression, Anxiety and Stress Scales questionnaires, YaHS:Yazd Health Study, TAMYZ:Taghzieh Mardom-e-Yazd food, BMI:Body Mass Index, FFQ:frequency questionnaire, IPAQ:International Physical Activity Questionnaire, MET:Metabolic Equivalent, MUFA:monounsaturated fatty acids, SFA:saturated fatty acids.

\section{Declarations}

\section{Acknowledgements}

The authors would like to thank all participants without whom this study was impossible.

\section{Financial support:}

The study was financially supported by the Department for Research, Shahid Sadoughi University of Medical Sciences (SSU). The funders had no role in the design, analysis or writing of this article.

\section{Availability of data and materials}

Available upon request.

\section{Authors' contributions}

ZD and $\mathrm{MH}$ prepared the proposal, obtained ethical approvals, applied for funding and wrote the manuscript. MH, AS AND MM conceived the idea and supervised the study. AA, ZD and MH were involved in study analysis. All authors read and approved the final manuscript. 
Ethics approval and consent to participate:

The survey was approved by the Ethics Committee of Shahid Sadoughi University of Medical Sciences, Yazd, Iran Informed consent was taken from participants

\section{Consent for publication:}

Not applicable

\section{Competing interests:}

The authors declare that there is no financial and conflict of interest.

\section{References}

1. Ferrari A, Somerville A, Baxter A, Norman R, Patten S, Vos T, et al. Global variation in the prevalence and incidence of major depressive disorder: a systematic review of the epidemiological literature. Psychological medicine. 2013;43(3):47181.

2. Thibaut F. Anxiety disorders: a review of current literature. Dialogues in clinical neuroscience. 2017;19(2):87.

3. Mohammadi M-R, Davidian H, Noorbala AA, Malekafzali H, Naghavi HR, Pouretemad HR, et al. An epidemiological survey of psychiatric disorders in Iran. Clinical practice and epidemiology in mental health. 2005;1(1):16.

4. Mofrad MD, Siassi F, Guilani B, Bellissimo N, Azadbakht L. Association of dietary phytochemical index and mental health in women: A cross-sectional study. British Journal of Nutrition. 2019;121(9):1049-56.

5. Banta JE, Segovia-Siapco G, Crocker CB, Montoya D, Alhusseini N. Mental health status and dietary intake among California adults: A population-based survey. International journal of food sciences and nutrition. 2019;70(6):759-70.

6. Wattick RA, Hagedorn RL, Olfert MD. Relationship between diet and mental health in a young adult appalachian college population. Nutrients. 2018;10(8):957.

7. Zhu F, Du B, Xu B. Anti-inflammatory effects of phytochemicals from fruits, vegetables, and food legumes: A review. Critical reviews in food science and nutrition. 2018;58(8):1260-70.

8. Zhang H, Tsao R. Dietary polyphenols, oxidative stress and antioxidant and anti-inflammatory effects. Current Opinion in Food Science. 2016;8:33-42.

9. Abshirini M, Mahaki B, Bagheri F, Siassi F, Koohdani F, Sotoudeh G. Higher intake of phytochemical-rich foods is inversely related to prediabetes: A case-control study. International journal of preventive medicine. 2018;9.

10. Collins BM, McLachlan JA, Arnold SF. The estrogenic and antiestrogenic activities of phytochemicals with the human estrogen receptor expressed in yeast. Steroids. 1997;62(4):365-72.

11. Aghababayan S, Sheikhi Mobarakeh Z, Qorbani M, Abbasvandi F, Tiznobeyk Z, Aminianfar A, et al. Dietary Phytochemical Index and Benign Breast Diseases: A Case-Control Study. Nutrition and cancer. 2019:1-7.

12. McCarty MF. Proposal for a dietary "phytochemical index". Medical hypotheses. 2004;63(5):813-7.

13. Postorino M, Marino C, Tripepi G, Zoccali C, Group CW. Abdominal obesity modifies the risk of hypertriglyceridemia for all-cause and cardiovascular mortality in hemodialysis patients. Kidney international. 2011;79(7):765-72.

14. Bahadoran Z, Mirmiran P, Tohidi M, Azizi F. Dietary phytochemical index and the risk of insulin resistance and $\beta$-cell dysfunction: a prospective approach in Tehran lipid and glucose study. International journal of food sciences and nutrition. 2015;66(8):950-5.

15. Firth J, Veronese N, Cotter J, Shivappa N, Hebert J, Ee C, et al. What is the role of dietary inflammation in severe mental illness? a review of observational and experimental findings. Frontiers in psychiatry. 2019;10:350.

16. Slavich GM, Irwin MR. From stress to inflammation and major depressive disorder: a social signal transduction theory of depression. Psychological bulletin. 2014;140(3):774.

Page $7 / 15$ 
17. Mirzaei M, Salehi-Abargouei A, Mirzaei M, Mohsenpour MA. Cohort Profile: The Yazd Health Study (YaHS): a populationbased study of adults aged 20-70 years (study design and baseline population data). International journal of epidemiology. 2018;47(3):697-8h.

18. Ghaffarpour M, Houshiar-Rad A, Kianfar $\mathrm{H}$. The manual for household measures, cooking yields factors and edible portion of foods. Tehran: Nashre Olume Keshavarzy. 1999;7:213.

19. Farhangi MA, Najafi M, Jafarabadi MA, Jahangiry L. Mediterranean dietary quality index and dietary phytochemical index among patients candidate for coronary artery bypass grafting (CABG) surgery. BMC cardiovascular disorders. 2017;17(1):114.

20. Henry JD, Crawford JR. The short-form version of the Depression Anxiety Stress Scales (DASS-21): Construct validity and normative data in a large non-clinical sample. British journal of clinical psychology. 2005;44(2):227-39.

21. Moghaddam MB, Aghdam FB, Jafarabadi MA, Allahverdipour H, Nikookheslat SD, Safarpour S. The Iranian Version of International Physical Activity Questionnaire (IPAQ) in Iran: content and construct validity, factor structure, internal consistency and stability. World applied sciences journal. 2012;18(8):1073-80.

22. Hosseinzadeh M, Vafa M, Esmaillzadeh A, Feizi A, Majdzadeh R, Afshar H, et al. Empirically derived dietary patterns in relation to psychological disorders. Public health nutrition. 2016;19(2):204-17.

23. Chang S-C, Cassidy A, Willett WC, Rimm EB, O'Reilly EJ, Okereke OI. Dietary flavonoid intake and risk of incident depression in midlife and older women. The American journal of clinical nutrition. 2016;104(3):704-14.

24. Godos J, Castellano S, Ray S, Grosso G, Galvano F. Dietary polyphenol intake and depression: Results from the mediterranean healthy eating, lifestyle and aging (meal) study. Molecules. 2018;23(5):999.

25. Khosravi M, Sotoudeh G, Amini M, Raisi F, Mansoori A, Hosseinzadeh M. The relationship between dietary patterns and depression mediated by serum levels of Folate and vitamin B12. BMC psychiatry. 2020;20(1):1-8.

26. Mikolajczyk RT, El Ansari W, Maxwell AE. Food consumption frequency and perceived stress and depressive symptoms among students in three European countries. Nutrition journal. 2009;8(1):31.

27. Shivappa N, Hébert JR, Rietzschel ER, De Buyzere ML, Langlois M, Debruyne E, et al. Associations between dietary inflammatory index and inflammatory markers in the Asklepios Study. British Journal of Nutrition. 2015;113(4):665-71.

28. Kaplan BJ, Rucklidge JJ, Romijn A, McLeod K. The emerging field of nutritional mental health: Inflammation, the microbiome, oxidative stress, and mitochondrial function. Clinical Psychological Science. 2015;3(6):964-80.

29. Miller AH, Raison CL. The role of inflammation in depression: from evolutionary imperative to modern treatment target. Nature reviews immunology. 2016;16(1):22.

30. Maes M, Smith R, Scharpe S. The monocyte-T-lymphocyte hypothesis of major depression. Psychoneuroendocrinology. 1995.

31. Forni C, Facchiano F, Bartoli M, Pieretti S, Facchiano A, D’Arcangelo D, et al. Beneficial role of phytochemicals on oxidative stress and age-related diseases. BioMed research international. 2019;2019.

32. Bottiglieri T, Laundy M, Crellin R, Toone BK, Carney MW, Reynolds EH. Homocysteine, folate, methylation, and monoamine metabolism in depression. Journal of Neurology, Neurosurgery \& Psychiatry. 2000;69(2):228-32.

33. Gougeon L, Payette H, Morais JA, Gaudreau P, Shatenstein B, Gray-Donald K. A prospective evaluation of the depressionnutrient intake reverse causality hypothesis in a cohort of community-dwelling older Canadians. British Journal of Nutrition. 2017;117(7):1032-41.

34. Smaga I, Niedzielska E, Gawlik M, Moniczewski A, Krzek J, Przegaliński E, et al. Oxidative stress as an etiological factor and a potential treatment target of psychiatric disorders. Part 2. Depression, anxiety, schizophrenia and autism. Pharmacological Reports. 2015;67(3):569-80.

35. Halliwell B. Oxidative stress and neurodegeneration: where are we now? Journal of neurochemistry. 2006;97(6):1634-58.

36. Hodge A, Almeida OP, English DR, Giles GG, Flicker L. Patterns of dietary intake and psychological distress in older Australians: benefits not just from a Mediterranean diet. International psychogeriatrics. 2013;25(3):456-66. 
37. Geller S, Levy S, Goldzweig G, Hamdan S, Manor A, Dahan S, et al. Psychological distress among bariatric surgery candidates: The roles of body image and emotional eating. Clinical obesity. 2019;9(2):e12298.

38. Palmeira AL, Markland DA, Silva MN, Branco TL, Martins SC, Minderico CS, et al. Reciprocal effects among changes in weight, body image, and other psychological factors during behavioral obesity treatment: a mediation analysis. International Journal of Behavioral Nutrition and Physical Activity. 2009;6(1):9.

39. Son N. Assessment of body perception, psychological distress, and subjective quality of life among obese and nonobese subjects in Turkey. Nigerian journal of clinical practice. 2017;20(11):1302-8.

\section{Tables}

\begin{tabular}{|c|c|c|c|c|c|}
\hline \multicolumn{6}{|c|}{$\begin{array}{l}\text { Table1.The prevalence of depression, anxiety and stress across tertiles of DPI } \\
\text { DPI tertiles }\end{array}$} \\
\hline \multirow[t]{2}{*}{ P-value* } & T3 & $\mathrm{T} 2$ & $\mathrm{~T} 1$ & Total & Variable \\
\hline & & & & & Depression(n(\%)) \\
\hline \multirow[t]{3}{*}{0.33} & $191(8)$ & $179(7.5)$ & $208(8.7)$ & $578(8.1)$ & Yes \\
\hline & 2203(92) & 2199(87.1) & $2189(88.4)$ & 6591(91.9) & No \\
\hline & & & & & Anxiety $(n(\%))$ \\
\hline \multirow[t]{3}{*}{0.08} & $249(10.4)$ & $228(9.6)$ & $277(11.6)$ & $754(10.5)$ & Yes \\
\hline & $2145(89.6)$ & $2150(90.4)$ & $2120(88.4)$ & $6415(10.5)$ & No \\
\hline & & & & & Stress(n(\%)) \\
\hline \multirow[t]{2}{*}{0.57} & $77(3.2)$ & $74(3.5)$ & $87(3.6)$ & 238(3.3) & Yes \\
\hline & $2317(96.8)$ & $2304(96.9)$ & $2310(96.4)$ & 6931(96.7) & No \\
\hline
\end{tabular}

DPI, Dietary phytochemical index

*obtained from $\chi 2$ test 


\begin{tabular}{|c|c|c|c|c|c|c|c|c|c|}
\hline \multicolumn{10}{|c|}{ DPI tertiles } \\
\hline \multirow[t]{2}{*}{ P-value* } & \multicolumn{2}{|l|}{ T3 } & \multicolumn{2}{|l|}{$\mathrm{T} 2$} & \multicolumn{2}{|l|}{$\mathrm{T} 1$} & \multicolumn{2}{|l|}{ Total } & \multirow[t]{2}{*}{ Variable } \\
\hline & SD & mean & SD & mean & SD & mean & SD & mean & \\
\hline $0.01>$ & 14.61 & 73.54 & 14.49 & 72.63 & 14.84 & 72.05 & 5.09 & 72.74 & Weight(kg) \\
\hline $0.01>$ & 5.06 & 27.35 & 4.98 & 26.84 & 5.21 & 26.81 & 5.09 & 27.00 & BMI(kg/m2) \\
\hline 0.87 & 929.33 & 899.16 & 887.64 & 895.66 & 898.30 & 908.59 & 905.16 & 901.16 & MET_min/week \\
\hline \multirow[t]{6}{*}{0.02} & & & & & & & & & $\operatorname{age}(\mathrm{n}(\%))$ \\
\hline & \multicolumn{2}{|c|}{ 488(19.81) } & \multicolumn{2}{|c|}{$533(21.7)$} & \multicolumn{2}{|l|}{$565(22.9)$} & \multicolumn{2}{|c|}{$1584(21.5)$} & $20-29$ years \\
\hline & \multicolumn{2}{|c|}{$520(21.1)$} & \multicolumn{2}{|c|}{$506(20.6)$} & \multicolumn{2}{|l|}{$572(23.2)$} & \multicolumn{2}{|c|}{ 1598(21.6) } & 30_39 years \\
\hline & \multicolumn{2}{|c|}{ 494(920) } & \multicolumn{2}{|c|}{$551(22.5)$} & \multicolumn{2}{|l|}{$541(21.9)$} & \multicolumn{2}{|c|}{ 1586(21.5) } & 40_49 years \\
\hline & \multicolumn{2}{|c|}{$447(18.1)$} & \multicolumn{2}{|l|}{$467(19)$} & \multicolumn{2}{|l|}{ 488(19.3( } & \multicolumn{2}{|c|}{ 1402(19) } & $50-59$ years \\
\hline & \multicolumn{2}{|c|}{$389(15.8)$} & \multicolumn{2}{|c|}{$395(15.6)$} & \multicolumn{2}{|l|}{$431(17.5)$} & \multicolumn{2}{|c|}{$1215(16.4)$} & 60_69 years \\
\hline 0.49 & & & & & & & & & Marriage(n(\%)) \\
\hline & $270(10$ & & $301(11.9$ & & $258(11.3)$ & & $856(11$. & & Single \\
\hline & $2096(83$ & & $2072(82$. & & 2096(83) & & $6264(85$ & & married \\
\hline & $89(3.05)$ & & $75(3)$ & & $76(3)$ & & $240(3.3)$ & & Widowed or divorced \\
\hline 0.41 & & & & & & & & & smoking(n(\%)) \\
\hline & $2118(83$ & & 2103(83. & & $2107(83.5$ & & $113(1.6)$ & & Never smoker \\
\hline & 235(9.3) & & $260(10.3$ & & 271(10.7) & & $6238(78$ & & Current smoker \\
\hline & $43(1.7)$ & & $33(1.3)$ & & $37(1.5)$ & & $766(10$ & & Ex_smoker \\
\hline 0.05 & & & & & & & & & $\begin{array}{l}\text { Multi vitamin } \\
\text { supplment(n(\%)) }\end{array}$ \\
\hline & $2126(85$ & & $2159(88)$ & & $2122(85.4$ & & $6.407(8$ & & never \\
\hline & $163(6.5)$ & & $132(5.4)$ & & 187(7.5) & & $482(6.5)$ & & 1_3mount \\
\hline & $62(2.5)$ & & $54(2.2)$ & & $55(2.2)$ & & $171(2.3)$ & & Once a week \\
\hline & $13(0.5)$ & & $10(0.4)$ & & $13(0.5)$ & & $36(0.5)$ & & 2-4/week \\
\hline & $16(0.6)$ & & $9(0.4)$ & & $13(0.5)$ & & $38(0.5)$ & & 5_6/week \\
\hline & $88(3.5)$ & & $64(2.6)$ & & $57(2.3)$ & & $209(2.8)$ & & Once a day \\
\hline & $28(1.1)$ & & $24(1)$ & & $35(1.4)$ & & $87(1.2)$ & & Two a day \\
\hline & $4(0.2)$ & & $2(0.1)$ & & $2(0.1)$ & & $8(0.1)$ & & More than two a day \\
\hline 0.53 & & & & & & & & & gender(n(\%)) \\
\hline & $1219(49$ & & $1242(50$. & & $1212(49.1$ & & $3672(49$ & & men \\
\hline & $1242(50$ & & $12119(4 \mathrm{c}$ & .4) & $1258(50.9$ & & $3711(50$ & & Women \\
\hline 0.72 & & & & & & & & & Job(n(\%)) \\
\hline
\end{tabular}




\begin{tabular}{|c|c|c|c|c|c|}
\hline & $457(19)$ & $496(20.6)$ & $462(19)$ & $1415(19.5)$ & Unemployed \\
\hline & $1185(49.20)$ & $1169(48.5)$ & 1183(48.7) & $3537(48.8)$ & government employee \\
\hline & $78(3.2)$ & $79(3.3)$ & $90(3.7)$ & $247(3.4)$ & manual worker \\
\hline & $688(28.6)$ & $665(27.6)$ & $693(28.5)$ & 2046(28.2) & Freelance job \\
\hline \multirow[t]{6}{*}{0.10} & & & & & Education(n(\%)) \\
\hline & $573(23.3)$ & $593(24.3)$ & $610(24.8)$ & $1776(24.1)$ & illiterate \\
\hline & $670(27.2)$ & 708(29) & $717(29.2)$ & 2095(28.5) & Middle school \\
\hline & $789(32.1)$ & $739(30.3)$ & 761(30.9) & $2289(31.1)$ & Associate $\llbracket$ s degree \\
\hline & $344(14)$ & $332(13.6)$ & $319(13)$ & $995(13.5)$ & bachelor \s degree \\
\hline & $85(3.5)$ & $68(2.8)$ & $52(2.1)$ & $205(2.8)$ & 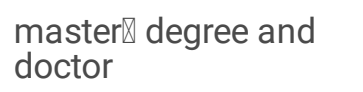 \\
\hline \multirow[t]{3}{*}{$0.01>$} & & & & & Special diet(n(\%)) \\
\hline & $386(18.93)$ & 280(13.92) & $415(24.48)$ & 1081(17.30) & Yes \\
\hline & 1653(81.06) & 1731(86.07) & $1280(75.51)$ & $5164(82.69)$ & No \\
\hline \multirow[t]{3}{*}{$0.01>$} & & & & & $\begin{array}{l}\text { History of chronic } \\
\text { disease(n(\%)) }\end{array}$ \\
\hline & $1157(45.8)$ & $1085(43)$ & 1042(41.3) & $4290(56.6)$ & Yes \\
\hline & $1368(54.2)$ & $1440(57)$ & $14.82(58.7)$ & $3284(43.4)$ & No \\
\hline
\end{tabular}

DPI, Dietary phytochemical index; BMI, body mass index

*Obtained from ANOVA for continuous variables and $\chi 2$ test for categorical variables. 


\begin{tabular}{|c|c|c|c|c|c|c|c|c|c|}
\hline \multicolumn{10}{|c|}{ DPI tertiles } \\
\hline \multirow[t]{2}{*}{ p_value* } & \multicolumn{2}{|l|}{ T3 } & \multicolumn{2}{|l|}{$\mathrm{T} 2$} & \multicolumn{2}{|l|}{$\mathrm{T} 1$} & \multicolumn{2}{|l|}{ Total } & \multirow[t]{2}{*}{ Variable } \\
\hline & SD & mean & SD & mean & SD & mean & SD & mean & \\
\hline $0.001>$ & 1344.04 & 2937.00 & 1284.49 & 2651.40 & 1463.82 & 3102.68 & 1378.62 & 2897.00 & $\begin{array}{l}\text { Energy } \\
\text { intake(kcal) }\end{array}$ \\
\hline $0.001>$ & 58.27 & 116.84 & 53.91 & 106.27 & 66.9 & 119.12 & 60.19 & 114.07 & Protein(g) \\
\hline $0.001>$ & 206.49 & 425.82 & 196.19 & 371.94 & 240.59 & 423.01 & 216.65 & 406.92 & Carbohydrate(g) \\
\hline $0.001>$ & 65.56 & 105.05 & 64.69 & 101.79 & 83.68 & 129.01 & 72.85 & 111.95 & Fat(g) \\
\hline $0.001>$ & 273.45 & 315.68 & 136.71 & 207.76 & 92.82 & 144.54 & 197.52 & 222.67 & $\begin{array}{l}\text { Energy intake of } \\
\text { fruits }\end{array}$ \\
\hline $0.001>$ & 162.45 & 95.75 & 67.04 & 66.00 & 46.84 & 54.95 & 106.40 & 72.24 & $\begin{array}{l}\text { Energy intake of } \\
\text { vegetables }\end{array}$ \\
\hline $0.001>$ & 104.07 & 69.35 & 51.06 & 51.30 & 40.22 & 42.46 & 71.71 & 54.37 & $\begin{array}{l}\text { Energy intake of } \\
\text { legumes }\end{array}$ \\
\hline $0.001>$ & 343.99 & 206.36 & 157.00 & 127.60 & 154.00 & 112.36 & 239.27 & 148.78 & $\begin{array}{l}\text { Energy intake of } \\
\text { nuts }\end{array}$ \\
\hline $0.001>$ & 412.28 & 321.83 & 118.32 & 141.15 & 87.49 & 105.00 & 269.93 & 189.34 & $\begin{array}{l}\text { Energy intake of } \\
\text { whole grain }\end{array}$ \\
\hline $0.001>$ & 15.38 & 28.42 & 15.58 & 28.62 & 22.23 & 36.09 & 18.36 & 31.04 & SFA (g) \\
\hline $0.001>$ & 25.83 & 30.08 & 21.83 & 26.13 & 25.32 & 30.17 & 24.46 & 28.79 & PUFA (g) \\
\hline $0.001>$ & 20.48 & 31.5 & 20.70 & 30.89 & 28.8 & 40.29 & 24.03 & 34.23 & MUFA (g) \\
\hline $0.001>$ & 295.73 & 364.34 & 300.01 & 368.05 & 526.38 & 452.29 & 391.32 & 394.88 & Cholesterol(mg) \\
\hline 0.36 & 70 & 20 & 70 & 20 & 90 & 20 & 70 & 20 & $\mathrm{EPA}(\mathrm{mg})$ \\
\hline 0.41 & 20 & 70 & 180 & 60 & 230 & 70 & 20 & 70 & $\mathrm{DHA}(\mathrm{mg})$ \\
\hline $0.001>$ & 42.55 & 32.44 & 24.14 & 20.53 & 29.60 & 18.34 & 33.59 & 23.77 & $\begin{array}{l}\text { Vitamin } \\
\text { A(RAE/day) }\end{array}$ \\
\hline $0.001>$ & 11.55 & 11.04 & 11.09 & 11.17 & 12.29 & 11.87 & 11.66 & 11.36 & $\begin{array}{l}\text { Vitamin E } \\
\text { (mg/day) }\end{array}$ \\
\hline $0.001>$ & 1.46 & 1.37 & 1.85 & 1.45 & 2.77 & 1.61 & 2.10 & 1.48 & Vitamin $\mathrm{D}(\mu \mathrm{g})$ \\
\hline 0.04 & 251.27 & 179.85 & 233.46 & 163.41 & 261.94 & 165.95 & 249.23 & 169.74 & Vitamin $\mathrm{K}$ \\
\hline $0.001>$ & 261.10 & 277.09 & 141.71 & 196.09 & 106.22 & 158.57 & 188.73 & 210.59 & Vitamin C (mg) \\
\hline $0.001>$ & 1.09 & 2.42 & 0.09 & 2.08 & 1.06 & 2.19 & 1.03 & 2.23 & VitaminB1(mg) \\
\hline $0.001>$ & 1.14 & 2.39 & 1.16 & 2.24 & 1.33 & 2.50 & 1.22 & 2.37 & VitaminB2(mg/) \\
\hline $0.001>$ & 14.69 & 29.53 & 13.75 & 26.27 & 17.44 & 29.65 & 15.45 & 28.48 & VitaminB3(mg/) \\
\hline $0.001>$ & 18.10 & 23.77 & 16.09 & 21.42 & 19.68 & 22.39 & 18.04 & 22.53 & Biotin(mg/day) \\
\hline $0.001>$ & 4.79 & 7.57 & 2.98 & 6.12 & 2.98 & 6.10 & 3.75 & 6.60 & $\begin{array}{l}\text { Pantothenic } \\
\text { acid(mg/day) }\end{array}$ \\
\hline $0.001>$ & 1.52 & 2.66 & 1.44 & 2.38 & 1.90 & 2.61 & 1.64 & 2.55 & VitaminB6(mg) \\
\hline
\end{tabular}




\begin{tabular}{|c|c|c|c|c|c|c|c|c|c|}
\hline $0.001>$ & 268.94 & 439.65 & 205.30 & 354.02 & 190.03 & 345.92 & 228.00 & 379.87 & Folic acid $(\mu \mathrm{g})$ \\
\hline $0.001>$ & 5.52 & 5.69 & 6.37 & 5.76 & 6.93 & 6.76 & 6.32 & 6.07 & $\operatorname{VitaminB12}(\mu \mathrm{g})$ \\
\hline $0.001>$ & 454.69 & 999.59 & 470.69 & 921.24 & 536.04 & 983.09 & 489.50 & 967.97 & Calcium (mg) \\
\hline $0.001>$ & 200.58 & 382.32 & 166.02 & 315.67 & 162.10 & 319.98 & 179.66 & 339.33 & $\begin{array}{l}\text { Magnesium } \\
\text { (mg) }\end{array}$ \\
\hline $0.001>$ & 6.14 & 12.50 & 5.28 & 11.07 & 6.52 & 12.26 & 6.03 & 11.94 & Zinc (mg) \\
\hline $0.001>$ & 97.93 & 52.55 & 40.63 & 38.47 & 94.63 & 38.55 & 82.30 & 43.19 & $\mathrm{Fe}(\mathrm{mg})$ \\
\hline
\end{tabular}

DPI: dietary phytochemical index; SFA: saturated fatty acid; PUFA: poly unsaturated fatty acid; MUFA; mono unsaturated fatty acid;

RAE: Retinol activity equivalents

*Obtained from ANOVA

Table 4. Odds ratio depression, anxiety and stress across tertiles of DPI (Multivariable-adjusted odds ratios and 95\% confidence intervals) 


\begin{tabular}{|c|c|c|c|c|}
\hline \multirow[t]{2}{*}{$\mathrm{P}$ trend $\neq$} & \multicolumn{3}{|l|}{ DPI tertile } & \multirow[t]{2}{*}{ Variable } \\
\hline & T3 & $\mathrm{T} 2$ & $\mathrm{~T} 1$ & \\
\hline & & & & $\mathrm{BMI} \leq 24.9$ \\
\hline & & & & Depression \\
\hline 0.04 & $0.69\left(0.48 \_1.00\right)$ & $0.71\left(0.50 \_1.01\right)$ & 1.00 & crude \\
\hline 0.03 & 0.69 (0.47_0.99) & $0.67\left(0.47 \_0.96\right)$ & 1.00 & Adjusted model1* \\
\hline \multirow[t]{2}{*}{0.02} & 0.65 (0.44_0.97) & $0.58\left(0.39 \_0.86\right)$ & 1.00 & Adjusted model2*ᄎ \\
\hline & & & & Anxiety \\
\hline 0.03 & 0.43 (0.51_0.98) & 0.75 (0.55_1.03) & 1.00 & crude \\
\hline 0.02 & $0.69\left(0.5 \_0.96\right)$ & 0.72(0.52_0.99) & 1.00 & Adjusted model1* \\
\hline \multirow[t]{2}{*}{0.01} & 0.65(0.45_0.93) & 0.65(0.46_0.93) & 1.00 & Adjusted model2*ᄎ \\
\hline & & & & Stress \\
\hline 0.90 & 0.81(0.47_1.41) & 0.83(0.49_1.4) & 1.00 & crude \\
\hline 0.43 & $0.81\left(0.47 \_1.40\right)$ & 0.78(0.45_1.33) & 1.00 & Adjusted model1* \\
\hline \multirow[t]{3}{*}{0.28} & 0.74(0.61_1.22) & 0.54(0.29_0.99) & 1.00 & Adjusted model2*ᄎ \\
\hline & & & & $\mathrm{BMI}>24.9$ \\
\hline & & & & Depression \\
\hline 0.80 & 1.03 (0.80_1.32) & $0.94\left(0.72 \_1.22\right)$ & 1.00 & crude \\
\hline 0.78 & $0.69\left(0.48 \_1.00\right)$ & $0.71\left(0.50 \_1.01\right)$ & 1.00 & Adjusted model* \\
\hline \multirow[t]{2}{*}{0.57} & $1.08\left(0.82 \_1.42\right)$ & 1.02 (0.77_1.35) & 1.00 & Adjusted model $2^{\star \star}$ \\
\hline & & & & Anxiety \\
\hline 0.82 & 0.97(0.78_1.28) & 0.84(0.67_1.06) & 1.00 & crude \\
\hline 0.99 & 0.97(0.78_1.21) & 0.84(0.67_1.07) & 1.00 & Adjusted model1* \\
\hline \multirow[t]{2}{*}{0.86} & 0.98(0.77_1.24) & 0.89(0.69_1.14) & 1.00 & Adjusted model2*ᄎ \\
\hline & & & & Stress \\
\hline 0.95 & 0.91(0.62_1.33) & 0.86(0.58_1.28) & 1.00 & crude \\
\hline 0.70 & 0.92(0.62_1.39) & 0.86(0.52_1.29) & & Adjusted model1* \\
\hline 0.99 & 0.99(0.65_1.51) & 0.94(0.61_1.65) & & Adjusted model2** \\
\hline
\end{tabular}


DPI: dietary phytochemical index

*Adjusted for age, gender and total energy intake.

** Adjusted for model 1 and marital status, physical activity, supplement use, history of chronic disease, smoking and special diet.

†These values are odds ratios (95\% Cls).

¥Obtained from logistic regression by considering tertiles of DPI as ordinal variable. 